\section{INTERVIEW WITH MARIE JONES}

\section{INTERVIEW BY ROGER GROS}

Roger Gros is the publisher of Global Gaming Business and is based in Las Vegas, Nevada, and Atlantic City, New Jersey.

arie Jones is a partner in the Atlan-
tic City office of Fox Rothschild,
one of the major law firms serving
the gaming industry across the
U.S. Jones works closely with regulators in New Jersey and Pennsylvania to understand the processes and procedures surrounding the lockdowns and reopenings. She is co-chair of the firm's Gaming Practice Group and has received many honors from prestigious legal groups, including Chambers USA, which recognizes her as one of the top gaming attorneys in the country.

ROGER GROS: We are looking at the situation that happened when COVID-19 hit in early March. Let's talk about what the regulators came up with. What kind of issues did they help the casinos with when it was time to shut down? I understand they did it in less than a day.

MARIE JONES: Yes, it came down very quickly. Luckily, the casinos do have protocols in place for shutdowns, mainly because of such things as hurricanes. In this instance, it was rather quick, and it was efficient. The regulators worked with the properties, their local on-staff, onsite DGE [Division of Gaming Enforcement] individuals to help them enforce those protocols, count the money, and, unfortunately, lock up the facilities for much longer than we had hoped.

ROGER GROS: Well, you know, it was not just hurricanes that they were prepared for, it was legislative shutdowns, as well, so hopefully that will not happen again, either.
MARIE JONES: Correct. That was a unique one, we hope.

ROGER GROS: What was some of the guidance that you gave your clients when the time came? What were some of the questions that they had?

MARIE JONES: They were: What did the executive order say? When did they have to do it? How quickly? Was it the standard protocol? Most of the clients already had their systems in place, so they were ready to shut down.

ROGER GROS: Some of the CEOs I have spoken with said that they had been anticipating this, so they had actually had plans in place that they could put into action when the word came.

MARIE JONES: You are right. And some of those facilities have had experience prior to this in other jurisdictions throughout the world that had already shut down. You know, Hard Rock, for example, had facilities outside the country that had to shut down already. So, as you said, they were anticipating it, and thinking about it prior to when the order was received.

ROGER GROS: How did the casinos stay in contact and engage with their employees during this period? Obviously, this is an important element of their operations, and they had to really be able to let them know what was going on.

MARIE JONES: All of them communicated well. Each property had its own system, but now with e-mail and text messaging, they stayed active with their employees. Most of the properties had some type of continuation of payment, salary payments, and benefits for them for at least some period of time.

Some of them did different benefits for the employees, such as Hard Rock. They had something that was well publicized where they gave employees under a certain income level gift cards and tried to continually engage, because not only was everyone in general concerned, but there was the additional anxiety of their jobs and what happens when they come back. 
ROGER GROS: Did you also advise them on some of the protocols, when they would furlough or lay off employees? We saw a raft of warn notices go out prior to layoffs. Was this something that you guys got involved in?

MARIE JONES: It is something that our employment lawyers got involved in, but the warn letters that have to go out are pretty standard. Once a certain amount of time went by, and it looked like this was going to continue, the properties had to do it.

ROGER GROS: The first shutdown order was for two weeks. It kept getting extended and extended until it was four months long. How did the casino prepare for reopening, and what were some of the compliance challenges that you guys had to help them with?

MARIE JONES: As soon as they shut down, they were already planning for reopening and how they were going to do it because, obviously, that was the most important goal. Once everybody was isolated and safe, let us look at how we can safely reopen.

Again, some of the properties have facilities in jurisdictions that were already starting to reopen, so they knew what they had to do, such as requiring masks, starting with the hand sanitizer stations, and starting to order Plexiglas and really looking at it.

A number of them had environmental health experts come in and work with them to come up with a protocol. Ultimately, they provided that protocol to the state, and then went back and forth with them, and then implemented it. They have done a good job. It was definitely a learning curve for everyone, and a unique time.

ROGER GROS: How much of a curveball was the no-indoor-dining stipulation that Governor Murphy added at the last minute?

MARIE JONES: That was definitely a curveball for them. The properties expected to be able to have indoor dining. Most of them were already looking at their outdoor dining and working with the city to expand that width — where the city would normally say only a certain amount, and it is usually right around that time in March, April that we start getting city approval for beach and boardwalk for the season. That actually expanded. The city was very helpful with that and willing to work with the properties.

But look at Borgata as an example. They determined not to open because they did not feel that they would be able to adequately provide food service for their patrons outside, and they want to make sure that they have the right type of outdoor service. That was their choice, but that was definitely a curveball.

I also think it is going to end up expanding the outdoor service that will occur in the future. We have already seen it with allowing beverages - I will call it beverages - on the boardwalk. We have not used the outdoor services in South Jersey enough. Let us have something where we can look out at the ocean and eat. I think that this will actually push that along some.

Maybe that is a little silver lining in all of this.

ROGER GROS: The casinos had to get pretty creative, though. Ocean opened up a floor of their parking garage as outdoor dining. Did you have to advise them on what are the stipulations for outdoor dining were, whether there are two walls up or something like that?

MARIE JONES: We did. We had certain clientsand it is not just big casinos themselves, but they all have restaurant tenants that have outdoor-facing facilities, too. We advised on that, too- how best to structure it and to get whatever approvals they would need, either as a division or as a city to either expand what they had or to come up with some of these unique areas.

ROGER GROS: The casino environment is totally unlike it was previous to the shutdowns. You cannot drink on the casino floor. There seems to be a little bit of disparity in terms of what they allow people to bring onto the casino floor. Water bottles are approved, but are they personal water bottles? Are they water bottles that the casino gives away? How is this enforced, and what kind of stipulations do you have to advise your clients on?

MARIE JONES: Some of that came through the state mandate. Some of that is how the casinos operate and what they want to allow, if they want to allow somebody to bring something in. It is also up to the 
patron to sort of decide whether or not they should be taking their mask off and getting a drink of water or something like that.

You know, my preference - and this is just personalwould be to have them step outside to get a drink just for an extra precaution. But that is probably not feasible, and I am sure that the properties want to see them being allowed to have a cocktail and maybe do something unique with. It is really up to the guest services of the casino to approach the patron in a certain manner, and tell them, "This is what you are supposed to."

ROGER GROS: Are there instances of DGE agents on the floor observing what is going on and writing the casinos up?

MARIE JONES: I have not seen any DGE complaints at this point against any of the casino properties. The agents are on the floor and if they see somebody that is blatantly disregarding protocols, yes, it would be their job, as well as casino security's, to approach that patron and assist with the rules.

Nevada has had some casinos that have complaints filed against them by the regulators. At this point, I do not believe New Jersey has had any.

ROGER GROS: I think in Nevada, there were some complaints filed by private parties or something. Has that happened in New Jersey, people who are playing in the casino and see somebody violating, and then they report it to the DGE? How does that work? Do you know?

MARIE JONES: The first step would be for them to report it to the DGE person at the facility. And if it is not rectified at that point, they can file a patron complaint that would go to the Division of Gaming Enforcement, and then back to the property.

And again, so far, I have not been approached, and I do not think there has been a lot of those types of complaints, which is a good thing, but there is a mechanism in place for them, for the patrons to go to the regulators if they feel that a property-or another patron-is not doing something appropriate.

ROGER GROS: How about the beach bars? They were popular in the past. I understand they are even more popular now, since they are the only place you can go to drink. How is social distancing en- forced there? Do they have to wear masks, even though they are outside?

MARIE JONES: If you are outside and can be social distant, you do not have to wear a mask. The servers and the bartenders do. They have been trying to set the tables up and keep everybody apart. And just like the outdoor dining, they are allowed to not wear a mask at that point. It becomes a little bit more challenging when it gets busy, and there are people at the bar. Again, the security has been involved in trying to keep everybody doing what they are supposed to be doing.

Allowing the beverage containers on the boardwalk does help lessen the crowd at the beach bars.

ROGER GROS: So they can just walk up to the beach bar and get a drink and walk out. That makes it a lot easier to control, I would imagine.

\section{MARIE JONES: Yes.}

ROGER GROS: New Jersey now seems to be one of the states where the pandemic has subsided a bit. How will the relaxations of some of these stipulations come about? Is the governor going to say, "Okay, now we can all have indoor dining, with the certain stipulations that go along with that?"

MARIE JONES: As you have seen, Governor Murphy has been conservative in his approach in trying to make sure that the number of COVID cases don't escalate again. He went backwards a little bit on some social gathering, and that was not related to the casinos and their reopening. The house parties in North Jersey were really out of control.

That was causing the numbers to escalate. I think you will see him starting to loosen things and go to indoor dining and, hopefully, raise the capacity at casinos and other businesses, but it will be a gradual. $\mathrm{He}$ won't say, "Okay, just open all indoor dining." It is probably going to start at 25 or $50 \%$, and then gradually go up once we see that the number of cases continue to go down or flatten.

ROGER GROS: In Nevada, Governor Sisolak has decided to charge the bars and restaurants that violate these regulations rather than punishing the entire sector for a couple of violators. Do you think that will happen in New Jersey? 
MARIE JONES: That is already happening in New Jersey. There are complaints about local bars, especially initially, and restaurants. They were being fined, sitting aside the casino properties, outside of there. So there has been enforcement along that line.

If we see the numbers escalating and a lack of control of some of the tourists or summer vacationers, I think that changes it. Then it makes more sense to keep the restriction tighter than try to say, "This place is in violation, or that place is in violation."

ROGER GROS: The pandemic seems to be winding down a little bit, certainly even here in Nevada, where it got bad a few weeks ago. The cases are diminishing. How long do you think it is going to be before things get back to normal, if there is ever going to be a normal again?

MARIE JONES: Again, it goes back to vaccination. I think it will slowly start getting back to normal as people get more comfortable with the new norm until there is a vaccination. I am sure you had the same experiences that I did. At first, going into a supermarket during the pandemic with a mask on was nerve-racking. Now you have more comfort in doing it. That will expand into different areas. A full back to normal is going to come after there is either a vaccine or therapeutics. 